\title{
Photocatalytic Degradation of 2, 4-D and Transition of Endocrine Disruptive Activity Using Transcriptome Based Bioassay in Zebrafish Embryos
}

\author{
A. Saeed, I. Hashmi, H. R. Habibi, L. Yu, and G. Achari
}

\begin{abstract}
Dichlorophenoxyacetic acid (2, 4-D) is one of the most widely used halogenated agricultural chemicals around the world and a well known endocrine disrupting chemical (EDC). $\mathrm{TiO}_{2}$ based photocatalytic degradation of 2 , 4-D was carried out and residual endocrine disruptive (ED) activity was determined by an in vivo model of zebrafish embryos exposed to various concentrations of 2, 4-D and its degraded products from $5 \mathrm{hpf}$ (hours post fertilization) to 72 hpf. Quantitative Real Time PCR was carried out to determine the relative expression of Heat shock protein (HSP70) and Glutathione peroxidase (GPX) genes of zebrafish using B-actin as housekeeping gene. HSP 70 expression increased at $150 \mu \mathrm{g} / \mathrm{L}$ 2, 4-D concentration while the expression was significantly lowered after its photocatalytic degradation. GPX expression was not significantly altered. The results reveal the validity of HSP gene affected by 2, 4-D exposure and some probability of toxic potential of byproducts formed during its degradation.
\end{abstract}

Index Terms-2, 4-D, endocrine disruption, photocatalysis, zebrafish embryos.

\section{INTRODUCTION}

Aquatic environment is the ultimate sink for most environmental pollutants; therefore, several cases of endocrine disruption have been reported in aquatic organisms, particularly in various species of fish [1]. Advanced Oxidation Processes (AOPs) are the current water treatment technologies for remediation of aquatic pollution. These processes are based on the in situ generation of highly reactive transitory species for mineralization of refractory organic compounds [2]. P-25 $\mathrm{TiO}_{2}$ catalyst is used as a standard reference for comparisons of photo activity under different treatment conditions [3]. The fundamental mechanism involves the generation of electron hole pair which determines the occurrence of redox reactions of species adsorbed on the photocatalyst surface [4]. Pesticide contamination of surface waters from agricultural use is a problem of global importance and known to disturb the

Manuscript received April 29, 2014; revised June 9, 2014. This work was supported in part by the International Research Support Initiative Program (IRSIP) of Higher Education Commission (HEC) Pakistan and research grant of University of Calgary, AB, Canada

A. Saeed and I. Hashmi are with Institute of Environmental Science \& Engineering (IESE), School of Civil \& Environmental Engineering (SCEE), National University of Sciences \& Technology (NUST), Islamabad, Pakistan (e-mail: asmasaeed@iese.nust.edu.pk, imranhashmi@iese.nust.edu.pk).

H. R. Habibiis is with the Department of Biological Sciences, University of Calgary, 2500 University Drive N. W. Calgary, Alberta T3B 2V4, Canada(e-mail: habibi@ucalgary.ca).

L. Yu and G. Achari are with the Department of Civil Engineering, University of Calgary, 2500 University Drive N.W. Calgary, Alberta T3B 2V4, Canada (e-mail: Linyu@ucalgary.ca, gachari@ucalgary.ca). delicate balance of aquatic ecosystems and affect the health of aquatic organisms, such as fish [5]-[7]. Among different pesticides contaminating aquatic ecosystems, the phenoxyacetic herbicides comprise one of the largest groups of herbicides used globally. 2, 4-dichlorophenoxyacetic acid $(2,4-\mathrm{D})$ has been the most widely used pesticide for over 60 years and is present in more than 1500 formulations available in the market [8].

The World Health Organization (WHO) has recommended $30 \mu \mathrm{g} / \mathrm{L}$ as its maximum permissible concentration in drinking water [9]. Its toxicity on non-target organisms has been a topic of extensive research, with some studies suggesting that 2, 4-D can induce oxidative damage to animal tissues [10]-[15] and the measurements of antioxidative enzyme activities like glutathione peroxidase in fish have been used to assess the oxidative damage [16]. Currently, various biomarkers have been used to impartially measure endocrine disruptive potency and understand the underlying mechanisms [17]. Therefore in the present study the relative expression of GPX and HSP70 genes of zebrafish was measured for assessment of oxidative damage and members of HSP family are considered molecular biomarkers for toxicity associated with physical and chemical stressors [18]. To determine the residual effects of 2, 4-D, we performed its $\mathrm{TiO}_{2}$ based photocatalyic degradation in aqueous solution and determined transcriptomic alterations in zebrafish embryos. Zebrafish has become one of the most popular model organisms in ecotoxicology [19], [20] owing to its unique features, such as its rapid development, easy maintenance in the laboratory, large number of offspring, transparency of embryos and access to experimental manipulation.

\section{MAterials AND METHODS}

All protocols involving zebrafish embryos and adults were approved by the appropriate university animal care committee. Embryos were obtained from the wild type adult zebrafish purchased from local pet store. Fish was kept in a dechlorinated RO water recirculating system with 14:10 hr light and dark photoperiod. At 5 hours post fertilization (hpf), embryos were spiked with RO water containing respective concentrations of 2, 4-D along with control group. Mortality was counted and the system water with 2, 4-D solutions were changed daily till embryos were collected at $72 \mathrm{hpf}$ and snap frozen.

\section{A. Treatment of 2, 4-D, HPLC Analysis and Exposure}

The $20 \mathrm{ppm}$ aqueous solution was given UV-A treatment $(365 \mathrm{~nm})$ with $\mathrm{P}-25 \mathrm{TiO}_{2}(2 \mathrm{~g} / \mathrm{L})$ slurry in LED (Lithium 
Electron Diode) reactor for $3 \mathrm{hrs}$ according to [21].

The light intensity was $8.55 \times 10^{16} .2$, 4-D was identified and quantified using a Varian Prostar 210 HPLC instrument equipped with a $325 \mathrm{~nm}$ liquid chromatography (LC) UV visible detector. HPLC analysis showed the disappearance of 2, 4-D along with formation of photoproducts as shown in Fig.1. Stock solution of $20 \mathrm{ppm}$ concentration of 2, 4-D was diluted to 50, 100, 150 and $200 \mu \mathrm{g} / \mathrm{L}$ for exposure to zebrafish embryos. Similarly, UV treated 2, 4-D of 20 ppm stock was also diluted to the similar concentrations and used for the exposure in parallel to determine the variation in expression due to $\mathrm{UV} / \mathrm{TiO}_{2}$ treatment of 2, 4-D.

\section{B. RNA Extraction and Reverse Transcription}

Total RNA was extracted using TRIZOL reagent (Invitrogen Scientific) according to manufacturer's instructions. The quality of RNA was determined by spectrophotometric readings at 260 and $280 \mathrm{~nm}$. After performing this analysis, the good quality RNA was used for cDNA synthesis. Four $\mu \mathrm{g}$ of total RNA was reverse transcribed in a total volume of $18 \mu \mathrm{l}$, using an oligo $\mathrm{d}(\mathrm{T})$ anchor and M-MLV reverse transcriptase (Invitrogen, Burlington, ON, Canada) according to manufacturer's protocol. The resulting cDNA was diluted three fold and stored at $-20{ }^{\circ} \mathrm{C}$ for use in QPCR.

\section{Statistical Analysis}

Statistical analysis was performed using one way ANOVA and two ways ANOVA to find difference among means of mRNA levels for various 2, 4-D concentrations and effect of UV treatment respectively. When ANOVA showed the presence of significant difference ( $p$ less than 0.05 ), post hoc multiple comparison of the mean was performed using the Tukey's test (Prism statistical software, Graph Pad Software, Inc., La Jella, CA, USA).

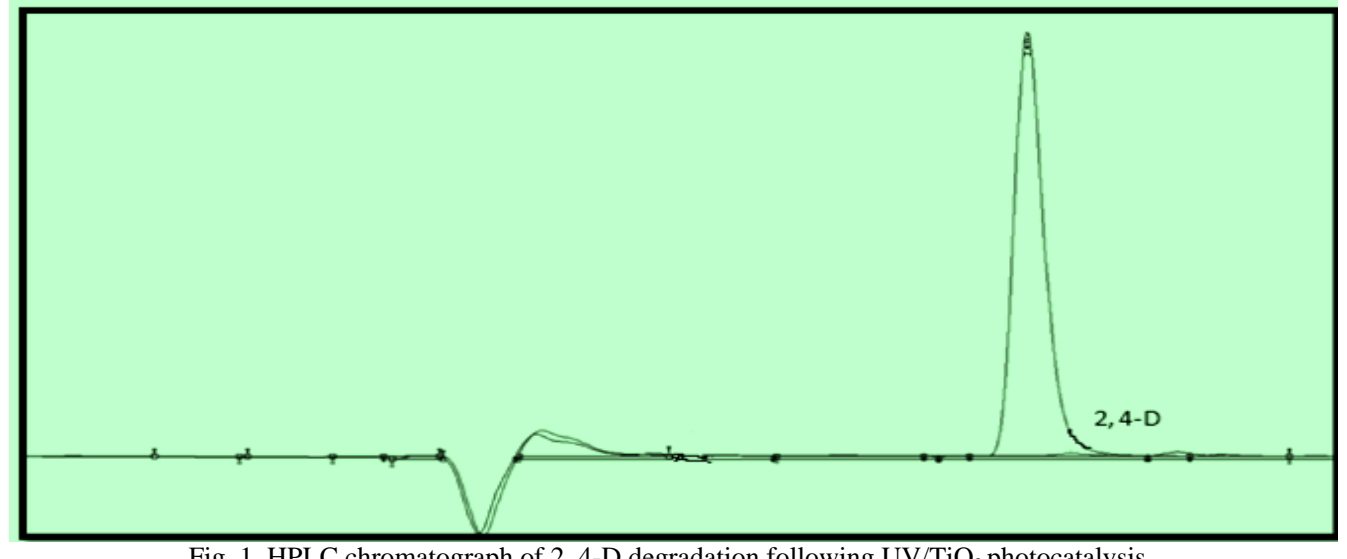

Fig. 1. HPLC chromatograph of 2, 4-D degradation following $\mathrm{UV} / \mathrm{TiO}_{2}$ photocatalysis.

\section{Quantitative Real Time Polymerase Chain Reaction}

QPCR was conducted to determine the relative expression of mRNA levels from zebrafish embryos/larvae genes. Zebrafish $\beta$-actin gene was used as an internal control. All forward and reverse primers along with their optimized annealing temperatures are listed in Table I. PCR amplification was conducted using BIORAD I cycler Multicolor Real Time PCR Detection System (Bio, Rad, USA) and iQ TM SYBR Green Supermix (Bio-Rad, USA), according to the manufacturer's instructions. QPCR was carried out as follows, initial denaturation at $95{ }^{\circ} \mathrm{C}$ for $3 \mathrm{~min}$, 40 cycles of denaturation at $95^{\circ} \mathrm{C}$ for $10 \mathrm{~S}$, annealing at the gene specific temperature (Table I) for 20 seconds. The calibrated $\Delta \mathrm{Ct}$ value $(\Delta \Delta \mathrm{Ct})$ for each sample and internal controls $(\beta$-actin $)$ was calculated $\left[\Delta \Delta \mathrm{Ct}=2^{\wedge}-(\Delta \mathrm{Ct}\right.$ sample $-\Delta C$ t internal control)] [25].

To ensure that the primers amplified a single product, a melt curve was performed for every QPCR plate. The efficiencies of reactions were determined by performing the QPCR on serial dilutions of CDNA. All primers were optimized via gradient PCRs with zebra fish tissues and the efficiencies for all genes were between $90-105 \%$, which is considered in the optimal range for QPCR analysis.

\section{RESULTS AND DISCUSSION}

Zebrafish embryos were exposed to various concentrations of 2, 4-D based upon preliminary experiments, before and after $\mathrm{UV} / \mathrm{TiO}_{2}$ treatment and tested for mRNA levels reltive to $B$-actin using QPCR assay. The results show the ability of 2, 4-D and its derivtives, formed after degradation, to interfere with normal expression of tested zebrafish genes.

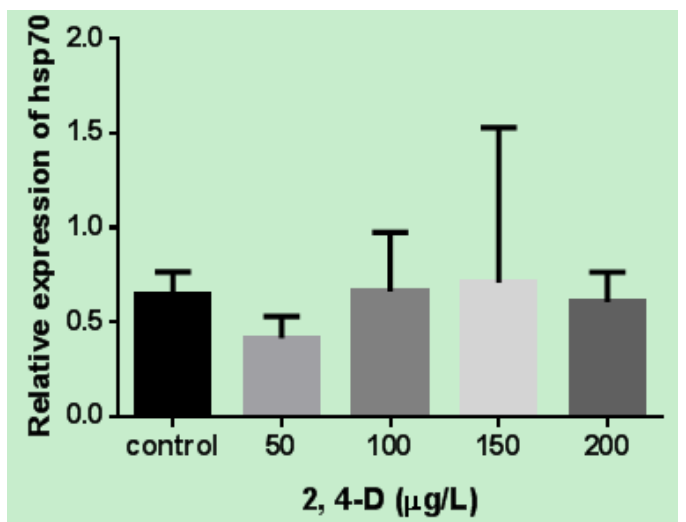

Fig. 2. Changes in the expression levels of Hsp70 gene in zebrafish showing control (No 2, 4-D) and various concentration of 2, 4-D exposed to zebra fish embryos till $72 \mathrm{hpf}$. The results are expressed as normalized gene expression levels with respect to the $\beta$-actin levels in the same samples All values are means $\pm \operatorname{SD}(n=5)$.

The relative expression of HSP70 gene was almost stable at applied 2, 4-D concentrations of 50 and $200 \mu \mathrm{g} / \mathrm{L}$ while an incresing trend was observed for 100 and $150 \mu \mathrm{g} / \mathrm{L}$ as shown in Fig. 2. Whereas, similar concentrations used for exposure after 2, 4-D degradation has resulted in significantly low 
expression $(p=0.0001)$, with almost 2 fold decrease at all exposure concentrations of $50,100,150$ and $200 \mu \mathrm{g} / \mathrm{L}$ as compared to control group with $p$ value of 0.0017 in one way ANOVA (Fig. 3). It indicates some different forms of toxic effects from 2, 4-D derivatives formed during its photocatalytic degradation. There are several degradation products from 2, 4-D such as, 1, 2, 4-benzenetriol, 2, 4-dichlorophenol, 2, 4-dichloroanisole, chlorohydroquinone (CHQ), 4-chlorophenol and volatile organics.

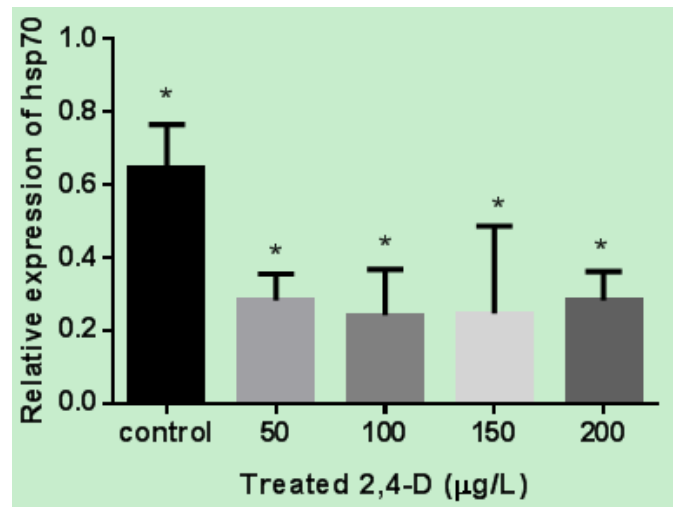

Fig. 3. Changes in the expression levels of Hsp70 gene in zebrafish showing control (No 2, 4-D) and various concentration of 2, 4-D after $\mathrm{UV} / \mathrm{TiO}_{2}$ treatment and exposed to zebrafish embryos till $72 \mathrm{hpf}$.The results are expressed as normalized gene expression levels with respect to the $\beta$-actin levels in the same samples. Values with asterisk are significantly different $(p<0.05)$. All values are means $\pm \mathrm{SD}(n=5)$.

The chronic health concerns with 2, 4-D and its derivatives have the potential for endocrine disruption. The expressions of HSP70, HSP40 and HSP90 in $C$. riparius were significantly increased after exposure to $10 \mu \mathrm{g} / \mathrm{L}$ concentration of 2, 4-D [26] indicating its ability to interfere with expression of heat shock genes. Figure 4 shows the curve shift for mRNA levels of HSP70 gene expression for the $\mathrm{UV} / \mathrm{TiO}_{2}$ treated and non treated 2, 4-D exposure to zebrafish embryos. Two ways ANOVA show the significant effect of treatment with $p$ value of 0.0017 , while there was no interaction between treated and non- treated groups and significant effect of dose on the mRNA expression of zebrafish HSP gene. Although, 2, 4-D has been suggested as a potential environmental endocrine disruptor and oxidative damage inducer [13] several studies have shown that 2, 4-D produces oxidative stress and depletes antioxidants both in vitro and in vivo exposures. In vivo oxidative activity has been studied in many species including yeast, plants, fish and rats [27-28-29]. The results show changes in HSP70 gene expression, as the exposure with treated 2, 4-D has resulted in significantly lower expression compared to control group.

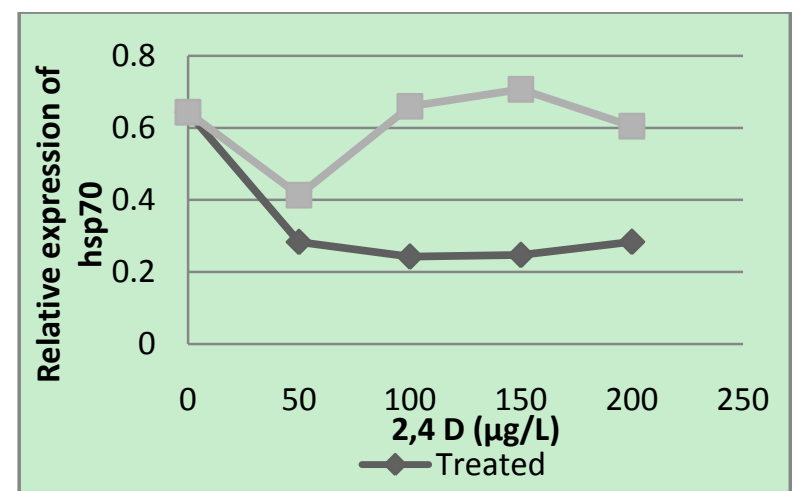

Fig. 4. Curve shift for Hsp70 m RNA levels due to UV treatment of 2, 4-D.

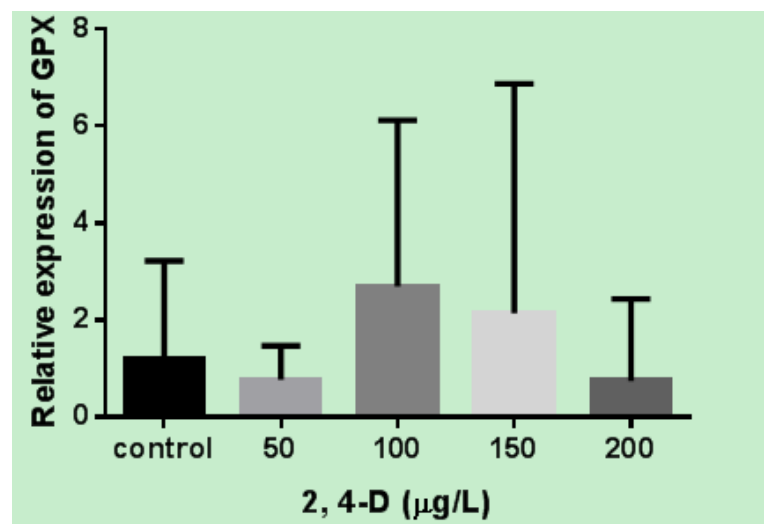

Fig. 5. Changes in the expression levels of GPX gene in zebrafish showing control (No 2, 4-D) and various concentration of 2, 4-D exposed to zebra fish embryos till $72 \mathrm{hpf}$. The results are expressed as normalized gene expression levels with respect to the $\beta$-actin levels in the same samples All values are means $\pm \operatorname{SD}(n=5)$

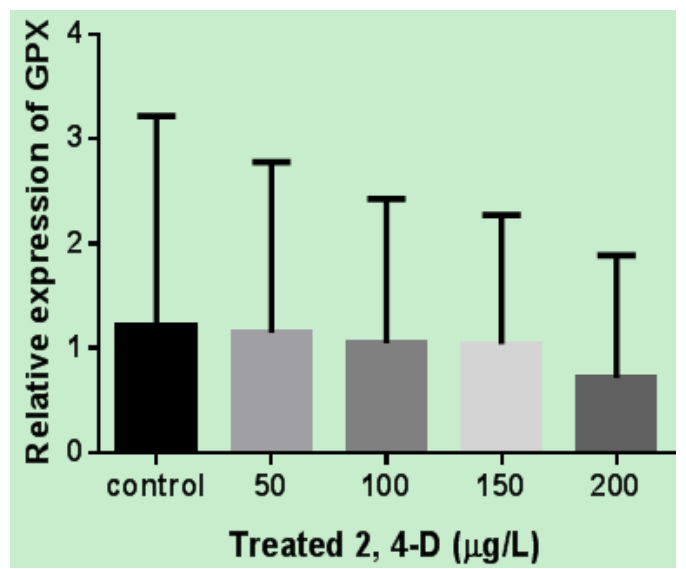

Fig. 6. Changes in the expression levels of GPX gene in zebrafish showing control (No 2, 4-D) and various concentration of 2, 4-D after $\mathrm{UV} / \mathrm{TiO}_{2}$ treatment and exposed to zebrafish embryos till $72 \mathrm{hpf}$.The results are expressed as normalized gene expression levels with respect to the $\beta$-actin levels in the same samples. Values with asterisk are significantly different $(p<0.05)$. All values are means $\pm \operatorname{SD}(n=5)$.

Fig. 5 shows the relative expression of GPX gene in zebrafish embryos exposed to various concentrations of 2 , 4-D. GPXexpression showed almost two fold increase compared to control group at $100 \mu \mathrm{g} / \mathrm{L}$ indicating its affinity for oxidative stress, also reported by other studies [12].

While in case of treated 2, 4-D, the expression remains almost unchanged (Fig. 6). Curve shift and 2 way ANOVA does not show significant difference among means of non treated and treated 2, 4-D exposure (Fig. 7). The p value is 1.323 for 2 way ANOVA, also there is no interaction and effect of dose among the mRNA levels of GPX for treated and non treated 2, 4-D exposure.

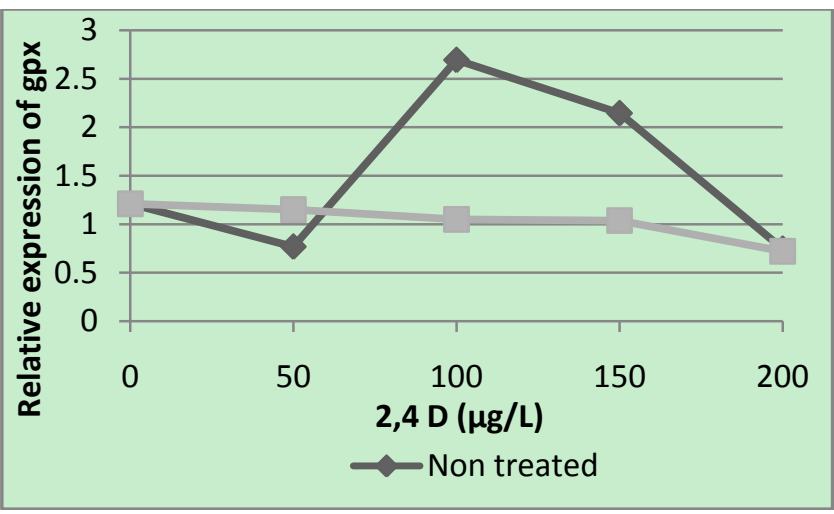

Fig. 7. Curve shift for GPX mRNA levels due to UV treatment of 2, 4-D. 
The results show disappearance of ED activity in case of GPX gene expression in zebrafish embryos as the mRNA levels are fairly in line with control group after the photocatalytic degradation of 2, 4-D. But the scenario is different for HSP70 gene where the exposure with treated 2, 4-D has resulted in significantly lower expression compared to control group.

Percent survival curve of zebrafish larvae exposed to 2, 4 $\mathrm{D}$ before and after $\mathrm{UV} / \mathrm{TiO}_{2}$ treatment has shown comparatively more survival in case of exposure with treated 2, 4-D. While non treated 2, $4 \mathrm{D}$ has resulted up to $40 \%$ mortality during exposure (Fig. 8) but the difference is not so obvious that it can be correlated with the complete removal of toxic effects after photocatalytic treament of 2, 4-D.

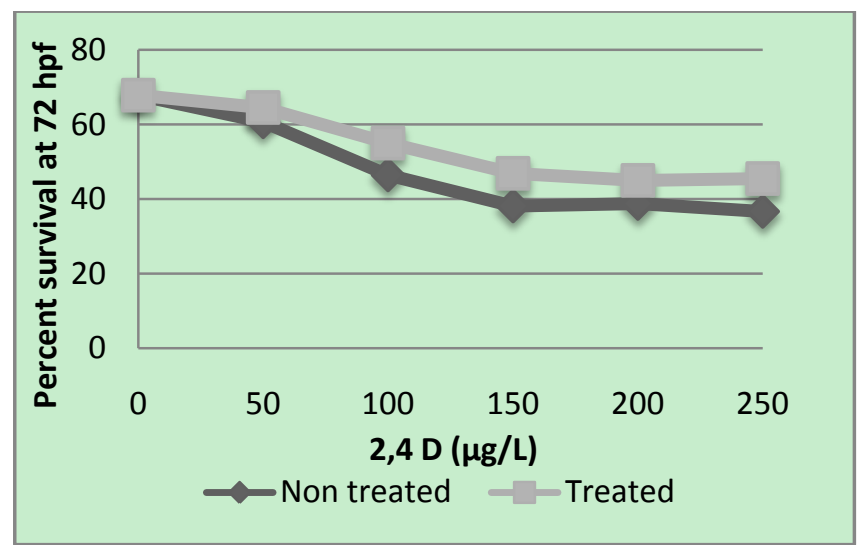

Fig. 8. Percent survival of zebrafish embryos/larvae at $72 \mathrm{hpf}$ after exposure with various concentrations of non treated and $\mathrm{UV} / \mathrm{TiO}_{2}$ treated 2, 4-D.

The photocatalytic degradation is found an efficient technique in ensuring the oxidative degradation of the benzene ring and the overall mineralization of aromatic compounds [30]. Thus the slurry type of $\mathrm{TiO}_{2}$ catalyst application is usually preferred due to high volumetric generation rate of reactive oxygen species (ROS) [31] as a result of the photo induced charge separation on $\mathrm{TiO}_{2}$ surfaces for mineralization of compounds without creating any secondary pollution. The post separation of the semiconductor $\mathrm{TiO}_{2}$ catalyst after water treatment remains as the major problem towards its practicality as an industrial process. It can be inferred by the results of treated 2, 4-D exposure to zebrafish embryos that some ED activity of 2, 4-D is contributed by its byproducts formed during its degradation as shown by the significantly altered expression of HSP70 gene. Furthermore, $\mathrm{TiO}_{2}$ based photocatalyticde gradation of 2, 4-D is an effective treatment method presenting altered gene expression in zebrafish embryos. Nonetheless, the need for further investigations for endocrine disruptive effects (ED) of individual byproducts formed during 2, 4-D degradation is still required.

\section{CONCLUSIONS}

The photocatalytic process of 2, 4-D degradation was evaluated using transcriptomic assay in zebrafish embryos and the expression of HSP70 and GPX genes in early life stages of zebrafish are found to be altered by 2, 4-D exposure. Furthermore, the transcriptomic activity of treated 2, 4-D suggests the possibility of some activity from its degradation byproducts. Systemic identification of individual degradation products and determination of their transcriptomic effects is recommended for comprehensive understanding of 2, 4-D degradation processes.

\section{ACKNOWLEDGMENT}

The research work was supported by the grant of Higher Education Commission of Pakistan under International Research Support Initiative Program (IRSIP) and additional funds for research work were provided from research grants of University of Calgary.

\section{REFERENCES}

[1] L. Sun, J. Jin, M. Zhao, and Z. Wang, "Interactions between estrogenic chemicals in binary mixtures investigated using vitellogenin induction and factorial analysis," Chemosphere, vol. 75, pp. 410-415, 2009.

[2] M. Pera-Titus, V. Garci'a-Molina, M. A. Ban os, J. Gime' nez, and S Esplugas, "Degradation of chlorophenols by means of advanced oxidation processes: a general review," Applied. Catalysis. B: Environment, vol. 47, pp. 219-256, 2004.

[3] N. Serpone, G. Sauve $\hat{A}^{\prime}$, R. Koch, H. Tahiri, P. Pichat, P. Piccinini, E Pelizetti, and H. Hidaka,. "Standardization protocol of process efficiencies and activation parameters in heterogeneous photocatalysis: relative photonic efficiencies," Journal of Photochemiastry and Photobiolog, A: Chemistry, vol. 94, pp. 191-203, 1996.

[4] R. A. Torres, J. I. Nieto, E. Combet, C. Pe'trier, and C. Pulgarin, "Influence of $\mathrm{TiO}_{2}$ concentration on the synergistic effect between photocatalysis and high frequency ultrasound for organic pollutant mineralization in water,"Applied Catalysis B: Environmental, vol. 80, pp. $168-175,2008$.

[5] S. Bretaudt, J. P. Toutant, and P. Saglio, "Effects of carbofuran, diuron and nicosulfuron on acetylcholinesterase activity in gold fish (Carassiusauratus)," Ecotoxicology \& Environmental Safety, vol. 47, pp. 117-124, 2000.

[6] E. O. Oruç and N. Üner, "Effects of 2, 4-diamin on some parameters of protein and carbohydrate metabolisms in the serum, muscle and liver of Cyprinuscarpio," Environmental Pollution, vol. 105, pp. 267-272, 1999.

[7] E. Sancho, C. Fernandez-Véga, M. Sanchez, M. D. Ferrando, and E. Andreu-Moliner, "Alterations on AChE activity of the fish Anguilla anguilla as response to herbicide contaminated water," Ecotoxicology \& Environmental Safety, vol. 46, pp. 57-63, 2000.

[8] W. Tayeb, I. Chaieb, and M. Hammami, "Environmental fate and effects of 2, 4-dichlorophenoxyacetic herbicide," in Herbicides: Properties, Crop Protection and Environmental Hazards, K. P. Piotrowsky, Ed. Nova Sciences Publisher, NY, 2011, pp. 161-187.

[9] USEPA, Supplementary Guidance for Conducting Health Risk Assessment of Chemical Mixtures, Washington DC, 2000.

[10] I. Munro, G. Carlo, J. Orr, K. Sund, R. Wilson, E. Kennepohl, B. Lynch, and M. Jablinske, "A comprehensive, integrated review and evaluation of the scientific evidence relating to the safety of the herbicide 2, 4-D," International Journal of Toxicology, vol. 11, pp 559-664, 1992

[11] E. O. Oruc, Y. Sevgiler, and N. U“ner, "Tissue specific oxidative stress responses in fish exposed to 2, 4-D and azinphosmethyl," Comparative Biochemistry and Physiology Part C, vol. 137, pp. 43-51, 2004.

[12] M. Teixeira, J. Telo, N. Duarte, and I. Sá-Correia, "The herbicide 2, 4 dichlorophenoxyacetic acid induces the generation of free-radicals and associated oxidative stress responses in yeast," Biochemical and Biophysical Research Communications, vol. 324, pp. 1101-1107, 2004.

[13] Y. Mi, C. Zhang, and K. Taya, "Quercetin protects spermatogonial cells from 2, 4-D induced oxidative damage in embryonic chickens," Journal of Reproduction and Development, vol. 53, pp. 749-754, 2007.

[14] M. C. Romero-Puertas, F. J. Corpas, M. Rodriguez-Serrano, M. Gomez, L. A. del Río, and L. M. Sandalio, "Differential expression and regulation of antioxidative enzymes by Cd in pea plants," Journal of Plant Physiology, vol. 164, pp. 1346-1357, 2007.

[15] I. Celik, Y. Tuluce, and I. Isik, "Influence of subacute treatment of some plant growth regulators on serum marker enzymes and erythrocyte and tissue antioxidant defense and lipid peroxidation in rats," Journal of Biochemistry and Molecular Toxicology, vol. 20, pp. 174-182, 2006.

[16] J. Zhang, H. Shen, X. Wang, J. Wu, and Y. Xue, "Effects of chronic exposure of 2, 4-dichlorophenol on the antioxidant system in liver of freshwater fish Carassiusauratus," Chemosphere, vol. 55, pp. 167-174, 2004. 
[17] E. Jung, B. An, H. Yang, K. Choi, and E. Jeung, "Biomarker Genes for detecting estrogenic activity of endocrine disruptors via estrogen receptors," International Journal of Environmental Research \& Public Health, vol. 9, pp. 698-711, 2012.

[18] S. Airaksinen, T. Jokilehto, C. M. I. Ra ${ }^{\circ}$ bergh, and M. Nikinmaa, "Heat and cold inducible regulation of HSP70 expression in zebrafish ZF4 cells," Comparative Biochemistry and Physiology, Part B, vol. 136, pp 275-282, 2003.

[19] P. Goldsmith, "Zebrafish as a pharmacological tool: the how, why and when," Current Opinion in Pharmacology, vol. 4, pp. 504-512, 2004.

[20] A. J. Hill, H. Teraoka, W. Heideman, and R. E. Peterson, "Zebrafish as a model vertebrate for investigating chemical toxicity," Toxicological Sciences, vol. 86, pp. 6-19, 2005.

[21] L. Yu, G. Achari, and C. H. Langford, "LED-based photocatalytic treatment of pesticides and chlorophenols," Journal of Environmental Engineering, vol. 139, pp. 1146-1151, 2013.

[22] B. R. Keegan, J. L. Feldman, D. H. Lee, D. S. Koos, R. K. Ho, D. Y. Stainier, and D. Yelon, "The elongation factors Pandora/Spt6 and foggy Spt 5 promote transcription in the zebrafish embryo," Development, vol. 129, pp. 1623-1632, 2002.

[23] J. A. Kreiling, R. Creton, and C. Reinisch, "Early Embryonic Exposure to Polychlorinated Biphenyls disrupts Heat-Shock Protein 70 Cognate Expression in Zebrafish," Journal of Toxicology and Environmental Health, Part A, vol. 70, pp. 1005-1013, 2007.

[24] B. F. Brammell and A. J. Wigginton, "Differential Gene Expression in zebrafish (Daniorerio) following Exposure to Gaseous Diffusion Plant Effluent and Effluent Receiving Stream Water," American Journal of Environmental Sciences, vol. 6, pp. 286-294, 2010.

[25] K. J. Livak and T. D. Schmittgen, "Analysis of relative gene expression data using real time quantitative PCR and the $2-\Delta \Delta C T$ method," Methods, vol. 25, pp. 402-408, 2001.

[26] K. Park, J. Park, J. Kim, and I. S. Kwak, "Biological and molecular responses of Chironomusriparius (Diptera, Chironomidae) to herbicide 2, 4-D (2, 4-dichlorophenoxyacetic acid)," Comparative
Biochemistry \& Physiology C- Toxicology \& Pharmacology, vol. 151, pp. 439-46, 2010.

[27] C. D. Nwani, N. S. Nagpure, R. Kumar, B. Kushwaha, and W. S Lakra, "DNA damage and oxidative stress modulatory effects of glyphosate-based herbicide in freshwater fish Channapunctatus," Environmental Toxicology \& Pharmacology, vol. 36, pp. 539-47, 2013.

[28] O. L. Kubrak, T. M.Atamaniuk, V. V. Husak, and V. I. Lushchak, "Transient effects of dichlorophenoxyacetic acid (2, 4-D) exposure on some metabolic and free radical processes in goldfish white muscle," Food and Chemical Toxicology, vol. 59, pp. 356-361, 2013.

[29] Anusuya and Hemalatha, "Effect of 2, 4-D pesticide on fish physiology and its antioxidant stress," World Journal of Fish and Marine Sciences, vol. 6, pp. 98-100, 2014.

[30] M. Bertelli and E. Selli, "Reaction paths and efficiency of photocatalysis on $\mathrm{TiO}_{2}$ and of $\mathrm{H}_{2} \mathrm{O}_{2}$ photolysis in the degradation of 2-chlorophenol," Journal of Hazardous Materials, B, vol. 138, pp. 46-52, 2006.

[31] L. D. Pozzo-Miller, N. Pivovarova, R. D. Leapman, R. A. Buchanan, T. S. Reese, and S. B. Andrews, "Activity dependent calcium sequestration in dendrites of hippocampal neurons in brain slices," Journal of Neuroscience, vol. 17, pp. 8729-8738, 1997.

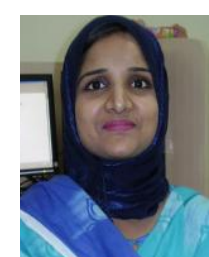

A. Saeed is a Ph.D. scholar in environmental engineering at Institute of Environmental Science and Engineering (IESE), School of Civil and Environmental Engineering (SCEE), National University of Sciences and Technology, (NUST), Islamabad. She got her MS degree in environmental engineering in 2009 from NUST and M.Phil degree in biotechnology 2004 from Quaid-e-Azam University, Islamabad, Pakistan. Her research interests include water quality, environmental toxicology, molecular techniques for detection of microbial contamination and toxic effects of pollution in water bodies. 